\title{
Originals
}

\section{Haemodynamic changes in insulin-induced hypoglycaemia in normal man}

\author{
J. Hilsted ${ }^{2,3}$, F. Bonde-Petersen1, M.-B. Nørgaard1, M.Greniman¹, N. J.Christensen ${ }^{5}$, H.-H.Parving4 and M.Suzuki ${ }^{1}$ \\ August Krogh Institute, University of Copenhagen; ${ }^{2}$ Surgical Department I and Department of Anaesthesia, Kommunehospitalet; \\ ${ }^{3}$ Hvidøre Hospital; ${ }^{4}$ Department of Clinical Physiology and Medical Department C, Bispebjerg Hospital; and \\ ${ }^{5}$ Department of Internal Medicine and Endocrinology F, Herlev Hospital, Copenhagen, Denmark
}

Summary. Haemodynamic variables (plasma volume, heart rate, blood pressure, cardiac output, stroke volume, pulmonary tissue volume, total peripheral vascular resistance, hepato-splanchnic vascular resistance, lower extremity vascular resistance and plasma catecholamines) were measured before and after insulin-induced hypoglycaemia in seven healthy men. Plasma volume decreased significantly at the nadir of glucose (mean decrease $222 \pm 41 \mathrm{ml}$ ) and subsequently increased to pre-hypoglycaemic values within $30 \mathrm{~min}$. Cardiac output increased in response to hypoglycaemia (mean increase $2.8 \pm 0.6 \mathrm{l} / \mathrm{min}$ ). The early rise in cardiac output was primarily due to an increase in heart rate, but later mainly due to increased stroke volume. Since pulmonary tissue volume was constant, the observed changes in cardiac output are unlikely to be due to a Frank-Starling mechanism but rather to increased sympatho-adrenal activity. Total peripheral vascular resistance as well as lower extremity vascular resistance decreased, whereas hepato-splanchnic vascular resistance was unaffected. Thus insulin-induced hypoglycaemia has marked transient effects on the circulation.

Key words: Insulin-induced hypoglycaemia, plasma volume, heart rate, cardiac output, cardiac stroke volume, blood pressure, plasma catecholamines, vascular resistance.
Insulin-induced hypoglycaemia - a frequent complication of insulin therapy - has profound effects on the circulation. Indeed, although infrequent, cardiac arrest and angina pectoris have been reported [1]. Previous investigations of haemodynamic events during hypoglycaemia have focussed mainly on the circulation in the extremities [2-4] and there are few reports on the central circulation $[1,5,6]$. The aim of the present study was to characterize the circulatory changes during hypoglycaemia in healthy subjects by means of simultaneous measurements of plasma volume, blood pressure, heart rate, cardiac output, pulmonary tissue volume, hepatosplanchnic blood flow, lower extremity blood flow and plasma catecholamines.

\section{Subjects and methods}

\section{Study population}

Seven healthy male students (age $22 \pm 0.6$ years, mean \pm SEM, height $180 \pm 3 \mathrm{~cm}$, weight $72 \pm 4 \mathrm{~kg}$ ) volunteered for the study after giving informed consent. The study was approved by the local Ethical Committee. The subjects were physically fit, maximal oxygen uptake $\left(\dot{V}_{\mathrm{O}_{2}}\right.$ max) determined during ergometer cycle exercise was $4.10 \pm 0.31 / \mathrm{min}$ (normal range $2.25-4.65 \mathrm{I} / \mathrm{min}$ ) or $57 \pm 3 \mathrm{ml} \cdot \mathrm{kg}^{-1} \cdot \mathrm{min}^{-1}$. None had a family history of diabetes mellitus, nor were they taking any drugs.

\section{Procedures}

Experiments were performed in the afternoon, the subjects having fasted and abstained from tobacco for at least $5 \mathrm{~h}$ before the study. A cannula was inserted into a cubital vein in each arm, whereupon they rested supine throughout the experiment. Room temperature was $25 \pm 1^{\circ} \mathrm{C}$. The patients wore shorts; blankets were not used. Over a period of $30 \mathrm{~min}$, the experimental procedures were explained to the subjects; subsequently, pre-hypoglycaemic measurements were made for $1 \mathrm{~h}$

Hypoglycaemia was induced by IV injection of soluble insulin (Actrapid, Novo) $0.15 \mathrm{IU} / \mathrm{kg}$ body weight. The following variables were determined:

Plasma volume was measured by means of ${ }^{125} \mathrm{I}$ - labelled serum albumin during the pre-hypoglycaemic period [7], and the haematocrit at this time was used in relation to subsequent determinations to estimate percentage change in plasma volume. Plasma protein concentrations were read refractometrically in triplicate with a total-solid meter (American Optical Corporation, Scientific Instrument Division, Buffalo, New York). No subject had interfering hyperlipaemia.

Arterial pressure was measured by the indirect auscultatory method, using a sphygmomanometer and a cuff. Mean arterial blood pressure (MAP) was calculated as: diastolic blood pressure $+1 / 3 \times$ (systolic - diastolic blood pressure)

Heart rate was registered continuously with precordial electrodes and displayed as the ECG on an oscilloscope (S\&W Diascope 521, Simonsen \& Weel, Copenhagen, Denmark). 

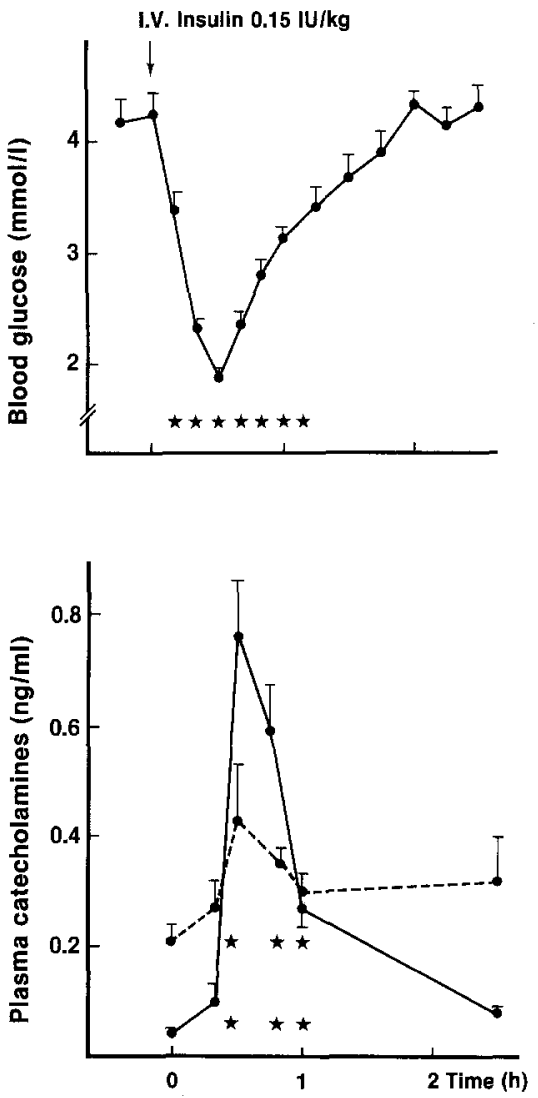

Fig. 1. Blood glucose concentrations and plasma concentrations of adrenaline (-O) and noradrenaline (-.) in seven healthy subjects before and after IV injection of $0.15 \mathrm{IU}$ insulin $/ \mathrm{kg}$ body weight. $* p<0.05$, significant changes from values obtained before injection of insulin

Cardiac output was measured as rate of acetylene wash-in into pulmonary capillaries, the subject rebreathing from a rubber bag at normal frequency and tidal volume [8]. Respiratory frequency and tidal volume were slightly increased at blood glucose nadir. Gas was sampled from the mouthpiece of the rubber bag and continuously analysed for acetylene, argon, oxygen and nitrogen in a mass spectrometer (Centronic MGA 200, 20th Century Electronics, Croydon, Surrey, UK). Coefficient of variation in 13 measurements of cardiac output was $5 \%$ in a normal subject.

Pulmonary tissue volume was calculated from gas fractions during rebreathing as the difference between distribution space for a watersoluble gas (acetylene) and a water-insoluble gas (argon) [9]. Coefficient of variation in 13 measurements of pulmonary tissue volume was $8 \%$ in a normal subject.

Total peripheral resistance (TPR) was estimated as mean arterial pressure/cardiac output, total peripheral vascular conductance $\left(\mathrm{TPR}^{-1}\right)$ as cardiac output/mean arterial pressure.

Hepato-splanchnic vascular resistance $\left(\mathrm{R}_{\mathrm{SPL}}\right)$. Hepato-splanchnic blood flow was estimated by measurements of peripheral Indocyanine Green (ICG) clearance after a bolus injection [10]. Plasma Indocyanine Green fractional clearance rate $(\mathrm{k})$ (disappearance rate constant) was calculated from the regression line (determined by the method of least squares) for the logarithmically transformed plasma concentrations versus time. Plasma clearance $(\mathrm{PC})$, which parallels hepatic blood flow, was then calculated from the equation $P C=k \times P V(P V:$ plasma volume). ICG is cleared from the circulation within 15 min of a bolus injection [10]; ICG was in the present study injected $7.5 \mathrm{~min}$ before every time point that a value is given for $\mathrm{R}_{\mathrm{SPL}}$ (Fig. 5). Estimated splanchnic vascular resistance $\mathrm{R}_{\mathrm{SPL}}$ was calculated
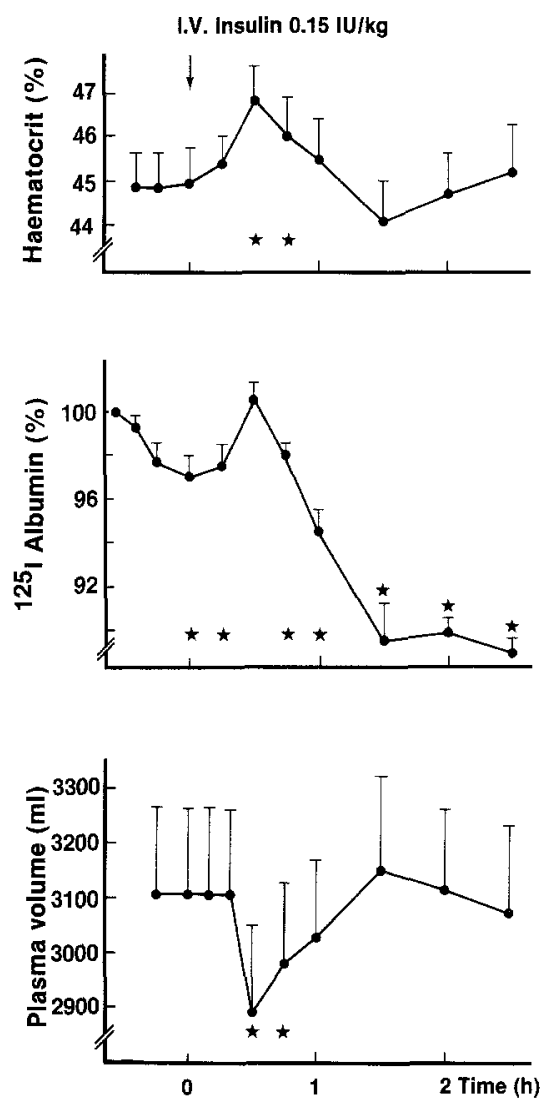

Fig. 2. Haematocrit, percentage change in activity of IV injected ${ }^{125} \mathrm{I}$ albumin and plasma volume before and after IV injection of 0.15 IU insulin $/ \mathrm{kg}$ body weight in seven healthy subjects. ${ }^{*} p<0.05$, significant changes from values obtained before injection of insulin

from the equation $\mathrm{R}_{\mathrm{SPL}}=\mathrm{MAP} /(\mathrm{k} \times \mathrm{PV}), \mathrm{R}_{\mathrm{SPL}}$ denoting resistance to plasma flow.

Lower extremity vascular resistance. Lower extremity blood flow $\left(F_{L E}\right)$ was measured by venous occlusion plethysmography [11]. Coefficient of variation in 13 measurements of lower extremity blood flow in normal subjects was $6 \%$. Lower extremity vascular resistance $\left(\mathrm{R}_{\mathrm{LE}}\right)$ was calculated from the equation

$$
\mathrm{R}_{\mathrm{LE}}=\frac{\mathrm{MAP}}{\mathrm{F}_{\mathrm{LE}}}
$$

Plasma concentrations of noradrenaline and adrenaline were determined by a single isotope derivative assay [12].

Glucose concentrations were measured by the hexokinase method [13].

Statistical analysis was made by Student's t-test for paired comparisons. The level of statistical significance chosen was $p<0.05$.

\section{Results}

The nadir of blood glucose was reached $30 \mathrm{~min}$ after IV insulin in all subjects (Fig. 1); by $2 \mathrm{~h}$ after insulin blood glucose levels had returned to normal levels.

Plasma adrenaline and noradrenaline increased significantly $30 \mathrm{~min}$ after insulin and returned to prehypoglycaemic levels $2 \mathrm{~h} 30 \mathrm{~min}$ after insulin (Fig. 1). 

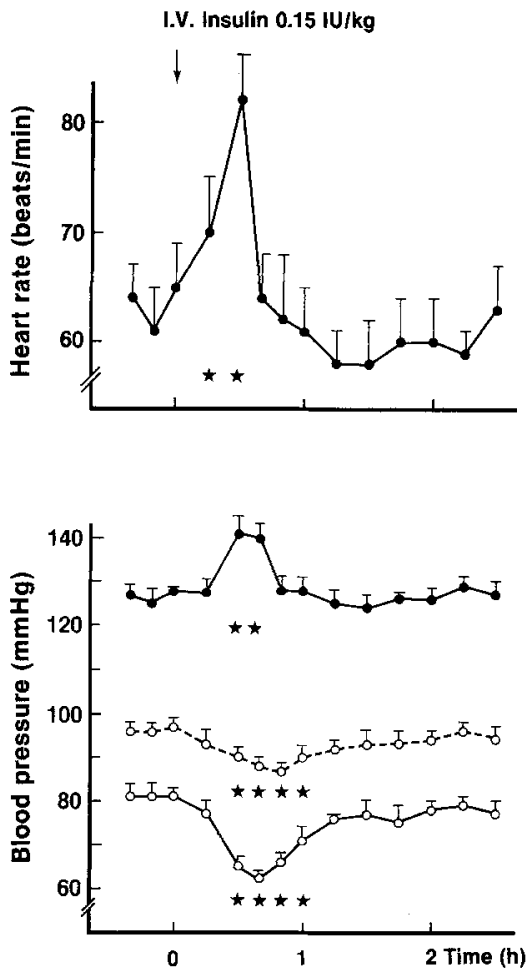

Fig.3. Heart rate and blood pressure before and after IV injection of $0.15 \mathrm{IU}$ insulin $/ \mathrm{kg}$ body weight in seven healthy subjects. ${ }^{*} p<0.05$, significant changes from values obtained before injection of insulin

Plasma volume decreased significantly (mean decrease $222 \mathrm{ml}$ ) at $30 \mathrm{~min}$ and returned to prehypoglycaemic values by $60 \mathrm{~min}$ after insulin (Fig. 2). No significant changes occurred in total intravascular protein mass (mean \pm SEM, $217 \pm 11 \mathrm{~g}$ before hypoglycaemia, $210 \pm 10 \mathrm{~g}$ at glucose nadir and $209 \pm 11 \mathrm{~g}$ after hypoglycaemia). The percentage ${ }^{125} \mathrm{I}$ - albumin activity in plasma $\left({ }^{125} \mathrm{I} / \mathrm{ml}\right.$ plasma at the various time points as a percentage of the value at time 0 in the pre-hypoglycaemic period) increased significantly from 20 to $30 \mathrm{~min}$ after insulin (Fig. 2).

Heart rate increased significantly $30 \mathrm{~min}$ after insulin and fell to pre-hypoglycaemic levels $10 \mathrm{~min}$ later (Fig. 3). Systolic blood pressure increased significantly $30 \mathrm{~min}$ after insulin and returned to pre-hypoglycaemic levels $20 \mathrm{~min}$ later, whereas diastolic blood pressure decreased significantly after insulin, minimum values being obtained $40 \mathrm{~min}$ after insulin. Pre-hypoglycaemic values were re-established $90 \mathrm{~min}$ after insulin. MAP decreased significantly, but was also normalized $90 \mathrm{~min}$ after insulin (Fig. 3).

The increments in systolic blood pressure and heart rate $30 \mathrm{~min}$ after insulin coincided with an increase in cardiac output. Cardiac output returned to basal levels within 60 min after insulin (Fig. 4).

Stroke volume increased later than cardiac output (40 min after insulin) and returned to basal in values at $60 \mathrm{~min}$ (Fig. 4). No significant changes occurred in pulmonary tissue volume (Fig. 4).
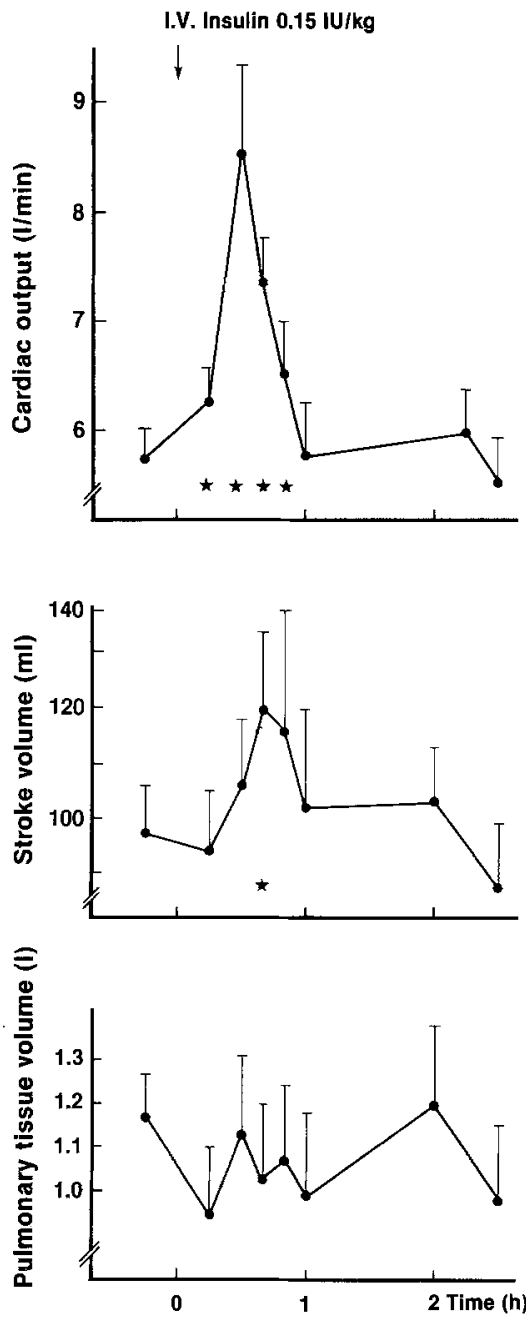

Fig.4. Cardiac output, cardiac stroke volume and pulmonary tissue volume in seven healthy subjects before and after IV injection of $0.15 \mathrm{IU}$ insulin $/ \mathrm{kg}$ body weight. $* p<0.05$, significant changes from values obtained before injection of insulin

A significant decrease was found in total peripheral resistance at $30 \mathrm{~min}$ after insulin, which became normal at $60 \mathrm{~min}$. The decrease in total peripheral resistance was paralleled by a decrease in lower extremity vascular resistance, while no significant changes were found in hepato-splanchnic vascular resistance (Fig. 5).

Total peripheral conductance increased significantly from $60 \pm 4$ to $82 \pm 61 \cdot \mathrm{min}^{-1} \cdot \mathrm{mmHg}^{-1} \cdot 10^{-3}$ at $30 \mathrm{~min}$ after insulin and returned to $62 \pm 5$ at $2 \mathrm{~h}$ after insulin. Lower extremity vascular conductance increased from $0.26 \pm 0.04$ to $0.46 \pm 0.04 \mathrm{ml} \cdot \mathrm{min}^{-1} \cdot \mathrm{mmHg}^{-1}$. $1000 \mathrm{~g}^{-1}$ tissue at $30 \mathrm{~min}$, returning to $0.29 \pm 0.03$ after $60 \mathrm{~min}$. Provided that vascular conductance increased in parallel in all four extremities and assuming a mean extremity weight of $8 \mathrm{~kg}$, the increase in extremity vascular conductance may account for $\frac{32 \times 0.20 \times 10^{-3}}{22 \times 10^{-3}} \times 100 \%=29 \%$ of the increase in total peripheral conductance. 

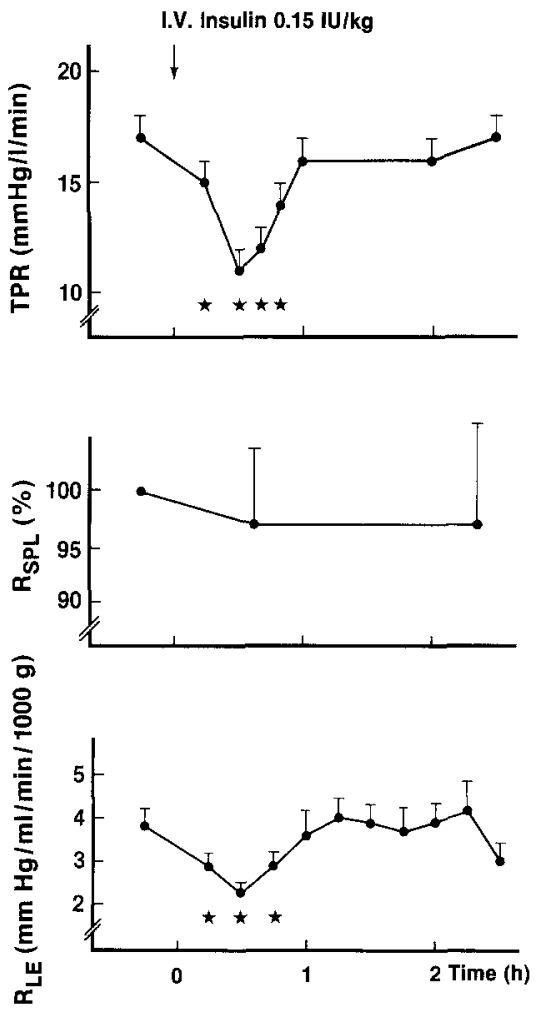

Fig.5. Total peripheral vascular resistance (TPR), percentage change in hepato-splanchnic vascular resistance $\left(\mathrm{R}_{\mathrm{SPL}}\right)$, and lower extremity vascular resistance $\left(R_{L E}\right)$ before and after IV injection of 0.15 IU insu$\mathrm{lin} / \mathrm{kg}$ body weight in seven healthy subjects. $\mathrm{R}_{\mathrm{SPL}}$ is given in percentage of values obtained before injection of insulin. $* p<0.05$, significant changes from values obtained before hypoglycaemia

\section{Discussion}

The present study has shown that insulin-induced hypoglycaemia is associated with a transient but significant reduction in plasma volume.

Previous investigations of the effect of insulin on plasma volume in diabetic subjects by three groups [14-16] have all used inravenous insulin in doses similar to ours. However, conflicting results were obtained in these reports, which are not directly comparable to the present study, because we found - in contrast to the previous ones - that blood glucose concentrations decreased to hypoglycaemic levels and plasma adrenaline increased. The increase in adrenaline is probably of major importance, since plasma volume decreases after intravenous injection of adrenaline [17].

The plasma volume changes in the present study may be ascribed to $\alpha$-adrenergic stimulation. It has been shown that infusions of catecholamines reduce plasma volume to an extent similar to that found in the present study, probably due to an increase in capillary pressure mediated by an increase in post-capillary resistance, together with a decrease in pre-capillary resistance [17]. Furthermore, in a recent study by Frier et al. [18] haematocrit responses to hypoglycaemia were abolished in patients with cervical cord transection, yet were intact in patients having undergone splenectomy as well as in normal man during $\beta$-receptor blockade. These findings suggest that autotransfusion of erythrocytes from the spleen does not contribute significantly to the increase in haematocrit observed during hypoglycaemia, whereas an intact sympathetic nervous system is essential for the reduction in plasma volume during hypoglycaemia. Since $\beta$-receptor blockade does not alter the plasma volume response, alpha-adrenergic stimulation may be mainly responsible for the plasma volume reduction during hypoglycaemia. Sweating may also contribute; an average sized man loses about $200 \mathrm{ml}$ of water during a hypoglycaemic reaction [19]. However, since this is lost from the total extracellular volume (about 491), the plasma volume reduction induced by sweating is probably small.

The increase in cardiac output in response to hypoglycaemia was similar to previous findings $[1,5]$. Cardiac output increased simultaneously with heart rate at glucose nadir whereas stroke volume increased $15 \mathrm{~min}$ later, indicating that during hypoglycaemia the early increase in cardiac output is mainly due to an increase in heart rate whereas later, cardiac output is elevated due to an increased stroke volume. Pulmonary tissue volume, which reflects central venous pressure [20], did not change significantly. It may therefore be concluded that the increase in cardiac output during hypoglycaemia is not due to a Frank-Starling mechanism but rather to the increased sympathoadrenal activity, resulting in increased heart rate and contractility.

The increase in lower extremity blood flow found in the present study is similar to earlier observations [2-4]. Since hand blood flow during hypoglycaemia is increased in normal man and decreased in sympathectomized man [2], it has been suggested that the increase in extremity blood flow is to a large extent due to withdrawal of vasoconstrictor tone. The lack of change in hepato-splanchnic vascular resistance observed in the present study and in a previous study [6] may suggest that withdrawal of vasoconstrictor tone does not occur in the hepato-splanchnic vascular bed or that withdrawal of vasoconstrictor tone is counteracted by vasoconstriction elicited by increased sympathoadrenal activity. It should be noticed however, that some hepatosplanchnic vasodilation may occur about $30 \mathrm{~min}$ after glucose nadir [6]. Vasoconstriction may result from circulating catecholamines or from stimulation of sympathetic nerves since circulating noradrenaline during hypoglycaemia is at least in part derived from sympathetic nerve endings [21].

Increases in total peripheral vascular conductance during hypoglycaemia were, judged from estimates of extremity mass and from hepato-splanchnic blood flow and lower extremity blood flow, larger than the increase in conductance in the hepato-splanchnic vascular bed and the lower extremities. Accordingly, increased vascular conductance in vascular areas not investigated in the present study (brain and kidneys) might contribute 
to the increase in total vascular conductance. Reliable human data on the circulation in these areas during hypoglycemia are lacking. Judged from animal studies however, a substantial increase occurs in cerebral blood flow during hypoglycaemia [22]. Alternatively, lower extremity blood flow may not be representative of total extremity blood flow.

In summary, in normal man insulin-induced hypoglycaemia is associated with a transient decrease in plasma volume, and an increase in cardiac output due to increase in heart rate and cardiac contractility. Hepato-splanchnic vascular resistance is unaffected, whereas lower extremity vascular resistance is decreased during hypoglycaemia. Increased cardiac output, haemoconcentration, hypercoagulability [23] and electrolyte shifts [24] may indicate a cardiac risk, associated with hypoglycaemia, especially in patients with overt cardiac disease and in the elderly.

Acknowledgements. We wish to thank Mrs. U.M.Smidt for technical assistance.

\section{References}

1. Ernstene AC, Altschule MD (1931) The effect of insulin hypoglycemia on the circulation. $J$ Clin Invest 10: 521-528

2. Allwood MJ, Ginsburg J, Paton A (1957) The effect of insulin hypoglycemia on blood flow in intact and sympathectomized extremities in man. J Physiol 139: 97-107

3. French EB, Kilpatrick R (1955) The role of adrenaline in hypoglycemic reactions in man. Clin Sci 14: 639-651

4. Middleton WG, French EB (1974) Studies of the peripheral vasodilator response to acute insulin-induced hypoglycemia in man. Clin Sci Mol Med 47: 461-470

5. Arner B, Hedner P, Karlefors T, Westling H (1963) Haemodynamic changes and adrenal function in man during induced hypoglycemia. Acta Endocrinol (Copenh) 44: 430-442

6. Bearn AG, Billing BH, Sherlock S (1951) The response of the liver to insulin in normal subjects and diabetes mellitus: Hepatic vein catherisation studies. Clin Sci 10: 151-165

7. Parving H-H, Rossing N, Nielsen SL, Lassen NA (1974) Increased transcapillary escape rate of albumin, IgG and IgM after plasma volume expansion. Am J Physiol 227: 245-250

8. Bonde-Petersen F, Norsk P, Suzuki Y (1980) A comparison between freon and acetylene rebreathing for measuring cardiac output. Aviat Space Environ Med 51:910-915

9. Sackner MA, Markwell G, Atkins N, Birch SJ, Fernandez RJ (1980) Rebreathing techniques for pulmonary capillary blood flow and tissue volume. J Appl Physiol 49: 910-915

10. Rowell LB, Blackmon JR, Bruce RA (1964) Indocyanine green clearance and estimated hepatic blood flow during mild to maximal exercise in upright man. J Clin Invest 43: 1677-1690

11. Bonde-Petersen F (1967) Blood flow in skin and muscle, evaluated by simultaneous venous occlusion plethysmography and Xe-133 clearance. Scand J Clin Lab Invest 19: 113-119

12. Christensen NJ, Vestergaard P, Sørensen T, Rafaelsen OJ (1980) Cerebrospinal fluid adrenaline and noradrenaline in depressed patients. Acta Psychiat Scand (1980) 61: 178-182

13. Schmidt FH (1961) Die enzymatische Bestimmung von Glucose und Fructose nebeneinander. Klin Wochenschr 39: 1244-1247

14. Gundersen HJG, Christensen NJ (1977) Intravenous insulin causing loss of intravascular water and albumin and increased adrenergic nervous activity in diabetics. Diabetes 26:551-557

15. Parving H-H, Noer I, Deckert T, Lassen NA (1979) Intravenous insulin has no effect on transcapillary escape rate of albumin and on plasma volume in short-term juvenile diabetics. Diabetes 28 : 282-286

16. MacKay JD, Hayakawa H, Watkins PJ (1978) Cardiovascular effects of insulin: Plasma volume changes in diabetics. Diabetologia 15: $453-457$

17. Cohn JN (1966) Relationship of plasma volume changes to resistance and capacitance vessel effects of sympathomimetic amines and angiotensin in man. Clin Sci 30: 267-278

18. Frier BM, Corrall RJM, McD Davidson N, Webber RG, Dewar A, French EB, Peripheral blood cell changes in response to acute hypoglycemia in man. Eur J Clin Invest (in press)

19. Corrall RJM, Frier BM, McD Davidson N, Hopkins WM, French EB (1983) Cholinergic manifestations of the acute autonomic reaction to hypoglycemia in man. Clin Sci 64:49-53

20. Weissler AM, McCraw BH, Warren JV (1969) Pulmonary blood volume determined by a radioactive tracer technique. J Appl Physiol 14: 531-539

21. Järhult J, Farnebo L-O, Hamberger B, Holst J, Schwartz TW (1981) The relation between catecholamines, glucagon and pancreatic polypeptide during hypoglycemia in man. Acta Endocrinologica 98: 402-406

22. Nilsson B, Agardh C-O, Ingvar M, Siesjö BK (1981) Cerebrovascular response during and following severe insulin-induced hypoglycemia: $\mathrm{CO}_{2}$ sensitivity, autoregulation and influence of prostaglandin synthesis inhibition. Acta Physiol Scand 111: 455-463

23. Hilsted J, Madsbad S, Dalsgaard Nielsen J, Krarup T, Sestoft L, Gormsen $J$ (1980) Hypoglycemia and hemostatic parameters in juvenile onset diabetics. Diabetes Care 3: 675-678

24. Petersen K-G, Schlüter KJ, Kerp L (1982) Regulation of serum potassium during insulin-induced hypoglycemia. Diabetes 31 : $615-617$

Received: 16 May 1983

and in revised form: 23 December 1983

Dr. J.Hilsted

Medical Department $F$

Glostrup Hospital

D-2600 Glostrup

Denmark 